\title{
Design definition and Manufacturing of the Superbus
}

\author{
Antonia Terzi, Valeria Antonelli, Wubbo Ockels
}

Delft University of Technology, The Netherlands

Copyright @ 2007 SAE International

\begin{abstract}
In this paper the structural design and the manufacturing aspects of the Superbus (Fig. 1) are presented. First the major aspects of the structural design are described alongside with the FEM model utilized. Then the materials utilized will be highlighted. Finally, the manufacturing of the various parts, namely chassis, bodywork and glazing will be described.
\end{abstract}

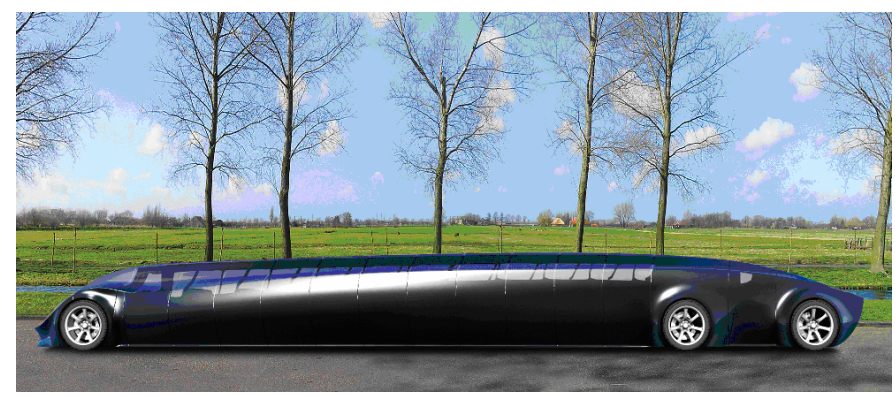

Fig 1: the Superbus

\section{INTRODUCTION}

The Superbus is a new public transportation: a nonpolluting, fast, and appealing vehicle developed in The Netherlands as proof of concept for the implementation of a new transportation system [1]. The Superbus has resulted to be the best option (the other options being the high speed train and the magnetic levitation train) for the Zuiderzeelijn. The latter is a fast transport connection between Amsterdam and Groningen that the Dutch Ministry of Transport and Water Management is intending to implement. Due to the novelty of the Superbus concept and the fact that it has never been realized, the Dutch Ministry of Transport and Water Management has decided to found the realization of a demonstrator of the vehicle that will be officially launched at the 2008 Beijing Olympics Games.

The Superbus concept [2] consists of a new vehicle, a new type of dedicated infrastructure and a new logistics.
The Superbus is sustainable, safe, and transports passengers and goods from point to point traveling on both its dedicated roads and on existing roads. The Superbus is not only sustainable for that it does not produce $\mathrm{CO} 2$ emissions but for many other aspects. For example, it uses some recyclable materials, it is designed to increase the use of public transportation, thus limiting the ever growing private transportation, and it uses low power per passenger.

The dedicated infrastructure, where the Superbus runs at $250 \mathrm{~km} / \mathrm{h}$, is cheaper than other high speed transportation means as it only consists of concrete roads with side barriers. The Superbus will drive at $250 \mathrm{~km} / \mathrm{h}$ on its dedicated roads and at conventional lower speeds on existing roads. This improves the public transportation in that there is no need to change transportation mean from starting to arrival point. With the Superbus, the vehicle that has covered the high speed part of the journey is also the one that will cover the lower speed parts of the journey, all the way to destination.

The logistics is new in many aspects. The Superbus does not have a fixed schedule. It is booked by phone or internet specifying departure and arrival locations, preferred departing time and type of seating (the Superbus has a number of seating layouts, from conference layout to leisure). The central control and communication system optimizes the route and departure time based on the locations of the Superbuses and the travel requests. Then the passenger receives a call or sms with precise departure time.

For the achievement of low consumption, the vehicle must be as light as possible. For that, the vehicle is designed to achieve the target design requirements with the minimum weight. Therefore the Superbus uses a composite chassis, IXIS bodywork (thermoplastic composite sandwich material which weighs half of the same part made of steal but it is equivalent in stiffness) and Lexan glazing (a polycarbonate based material preferred to glass for weight saving and safety). 


\section{SUPERBUS STRUCTURAL DESIGN}

The Superbus is $15 \mathrm{~m}$ long, $2.5 \mathrm{~m}$ wide and $1.6 \mathrm{~m}$ high. The vehicle carries 23 passengers and a driver and has 16 doors, 8 per side. The elevated number of doors is due to the required comfort, privacy, and accessibility aspects of this new type of vehicle. The overall vehicle weight is less than 9 tons, including the passengers.

The importance of the weight limitation of the vehicle has enforced the implementation of a new design and the use of lightweight materials.

The structure of the vehicle is composed by a carbon fiber chassis. It uses IXIS for the central part of the bodywork, carbon fiber for the front and rear bodywork and Lexan for the glazing.

For this phase of the project, namely the demonstrator, the load carrying structural part is the chassis. The bodywork and glazing have been considered as additional to the structural performance. This is not ideal for weight optimization, but the reason for it is that the materials for the bodywork and glazing (IXIS and Lexan) are new to this type of application.

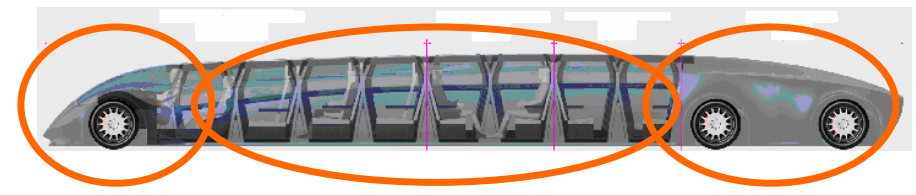

Fig 2: driver house, central cabin, rear section

In order to allow for the aerodynamic optimization of the front and rear part of the vehicle to be continued and defined after the initiation of the manufacturing process, the vehicle has been divided in three parts as shown in Figure2: driver house, central cabin and rear section.

The chassis (Figure3) is formed by a floor connected to 2 side frames united by 8 top beams.

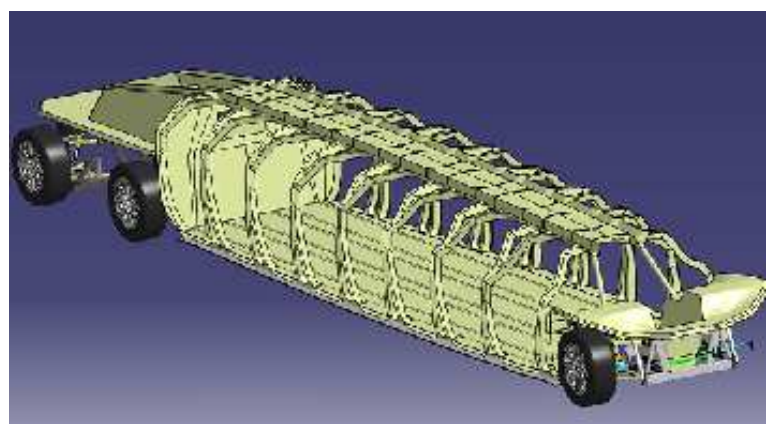

Figure 3: Chassis and suspension system

The floor is made of two skins inside which there are six longitudinal beams and 16 transversal beams. Each transversal beam is divided in seven parts to intersect the longitudinal beams.

The central part of the chassis is connected to the forward chassis part, the driver house, and the rear chassis part, which envelopes the powertrain compartment.

The set of load cases for the structural design definition has been grouped in stiffness requirements and strength requirements, as shown in Table 1.

Table 1: Load cases for demonstrator structural design

\begin{tabular}{|c|c|c|c|c|c|}
\hline \multicolumn{2}{|c|}{ Model Case } & \multicolumn{3}{|c|}{ Mass reaction } & \multirow[t]{2}{*}{ Criteria } \\
\hline & & $\mathbf{n x}$ & ny & $\mathrm{nx}$ & \\
\hline \multicolumn{6}{|c|}{ Stiffness requirements } \\
\hline 1 & $\begin{array}{l}\text { Torsion between axle } \\
\text { units }\end{array}$ & \multicolumn{3}{|c|}{$\begin{array}{l}\text { load at front } \\
\text { ground contacts }\end{array}$} & 30000Nmideg \\
\hline- & $\begin{array}{l}\text { Bending between axle } \\
\text { urits, (calculated }\end{array}$ & & & & 5 rurrig \\
\hline $\mathrm{x}$ & Vibration & all mas & sses in & volved & $\begin{array}{l}\text { range of } 20-30 \\
\mathrm{~Hz}\end{array}$ \\
\hline \multicolumn{6}{|c|}{ Load cases reacted on wheels / ground contact points } \\
\hline 2 & static & 0 & & & none \\
\hline 3 & Bump, front axle $3 \mathrm{~g}$ & & & match & h strength \\
\hline 4 & Burmp, rear axle $3 \mathrm{~g}$ & & & match & h strength \\
\hline & $\begin{array}{l}\text { Asymumetric inclined } \\
\text { road representing } 3 g \\
\text { case per wheel on one } \\
\text { set of diagonal }\end{array}$ & & & 1.5 & strength \\
\hline 6 & Breaking & -1 & & & strength \\
\hline 7 & Comering & & 1 & & strength \\
\hline 8 & $\begin{array}{l}\text { Side crash on } \\
\text { bumper, side load } \\
\text { reacted on one side } \\
\text { wheels }\end{array}$ & & 4 & & $\begin{array}{l}\text { strength on } \\
\text { wheel unit } \\
\text { attachments }\end{array}$ \\
\hline \multicolumn{6}{|c|}{ LOCAL ANALYSED Load cases reacted on wheels i grow } \\
\hline 9 & Abrupt stopping $4 g$ & -4 & & & $\begin{array}{l}\text { strength on } \\
\text { wheel urit } \\
\text { attachments }\end{array}$ \\
\hline 10 & $\begin{array}{l}\text { Windshield/Aero } \\
\text { force }\end{array}$ & $\begin{array}{l}\text { Aero lo } \\
3000 / 8 \\
\end{array}$ & 8000 & & $\begin{array}{l}\text { windshield } \\
\text { stresses }\end{array}$ \\
\hline
\end{tabular}

Through the design analyses and optimizations, the stiffness requirements have determined the overall vehicle structure design, whereas the strength requirements have driven the definition of the local details. The bending stiffness requirements were targeted to be met without the help of the closed doors. This was done to ensure that the opening of all doors at once, of the fully loaded vehicle, would not result in sudden loss of stiffness and subsequent bending under static load.

The design of the central part of the chassis (Figure 4) has proven significantly challenging for the presence of 
the 16 doors. As a result, the chassis frame design is made of crossbeams to enable the utilization of the entire vehicle cross section for torsion stiffness. This new design has been compared to a more conventional design formed by horizontal beams. The crossbeams design equates to a $40 \%$ weight reduction for the achievement of the target $30 \mathrm{kNm} / \mathrm{deg}$ torsional stiffness [3].

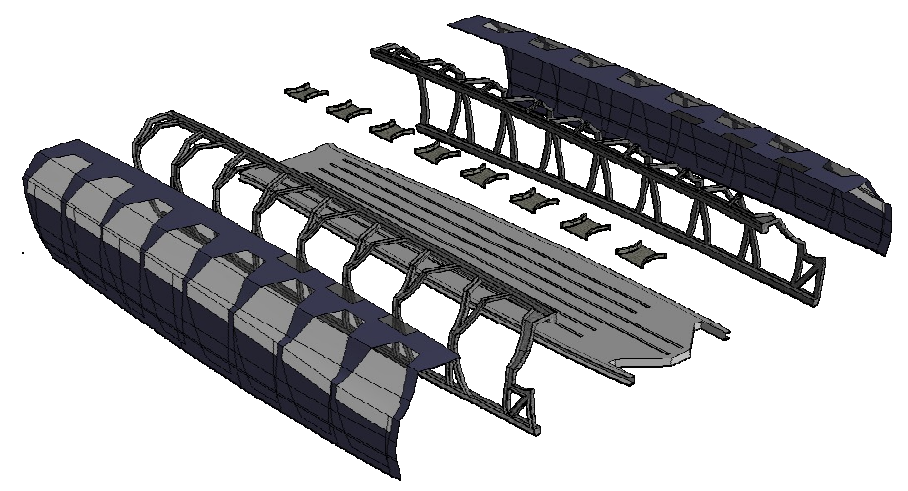

Figure 4: exploded view of the central section of the Superbus

The whole structure was analyzed with the use of Finite Element Analysis using MSC Patran as pre and post processor and MSC Nastran as FE code. The geometry of the Superbus structure has been designed in Solidworks and then merged with all systems and bodywork in CATIA V5. The final geometry has been imported in MSC Patran, Figure 5, where it has been meshed. All structural elements have been described using shell elements and applying material properties according to the exact production scheme. This choice defines the requirements for the geometry in the preprocessing phase and the quality of the finite element mesh. The resulting Supebus model consists of approximately 1.6 million DOF (degrees of freedom).

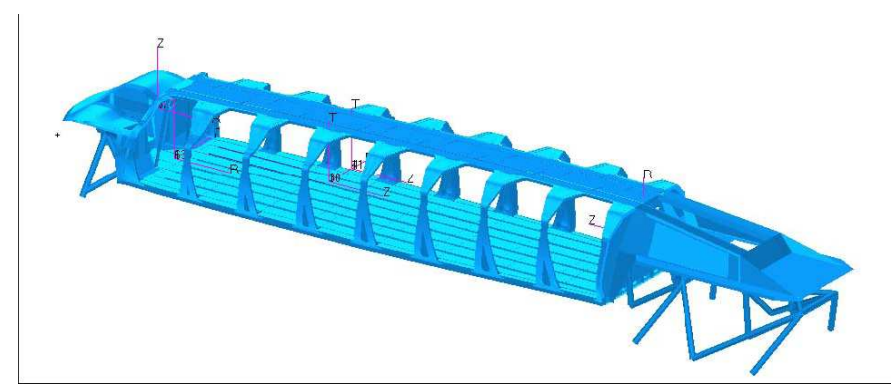

Figure 5: PATRAN FEM model

In the structural design model the suspension system has been represented by beam elements. The models for the FEM analyses have been prepared so to ensure that load introduction into the structure is in accordance to actual kinematics.

The geometry has been split in several top level groups to make the handling of the model easier.

The top level groups are: Side beams, Roof, Rear, Floor beam, Floor, Front.

In each top level group one half of the geometry has been deleted using the XZ-symmetry plane to ensure a fully symmetrical mesh when mirroring the elements after meshing. Where applicable the top level group has been subdivided in sub-groups where bonding flanges or local reinforcements of the structure were foreseeable. After the material lay-up definition was made, more groups were defined in order to support the simulation of various material thickness transition, material changes from fabric to UD or a mix of both. As an example, Figure 6 shows the overall sub-grouping of a section of the top beam connectors.

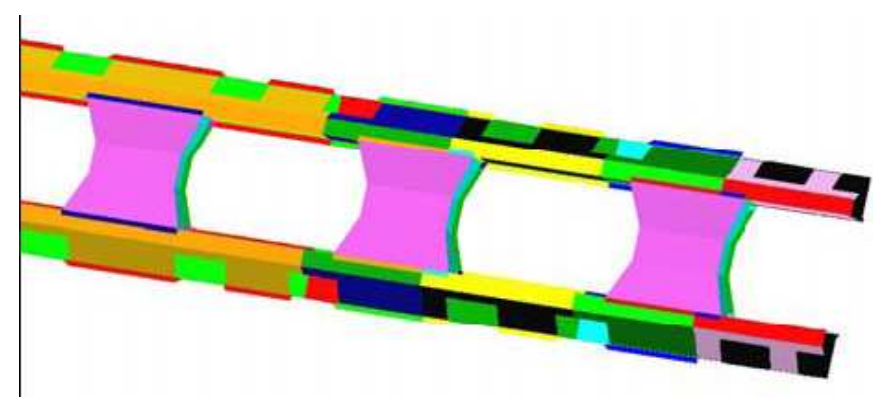

Figure 6: FEM model sub-groups definition of a section of the top beam connectors

The model comprises more than 250 different groups. Each group represents a unique material definition as the material properties change with every material layer.

In the analyses, the suspension has been assumed to be infinitely stiff as this assumption is considered to be conservative with regard to the stiffness and maximum stresses in the Superbus structure. A framework has been modeled to simulate the suspension, providing the appropriate degrees of freedom for each load case so to ensure the introduction of extra stiffness to the structure during the application of the boundary conditions.

With regard to processing time, the static analyses took approximately one hour using an Intel Dual-Core with 32 bits operative system. For the buckling and vibration analyses a cluster with four processors was used instead and running time was fifteen hours.

The initial results showed good stiffness performance with respect to torsion, Figure 7, but not with respect to bending. 


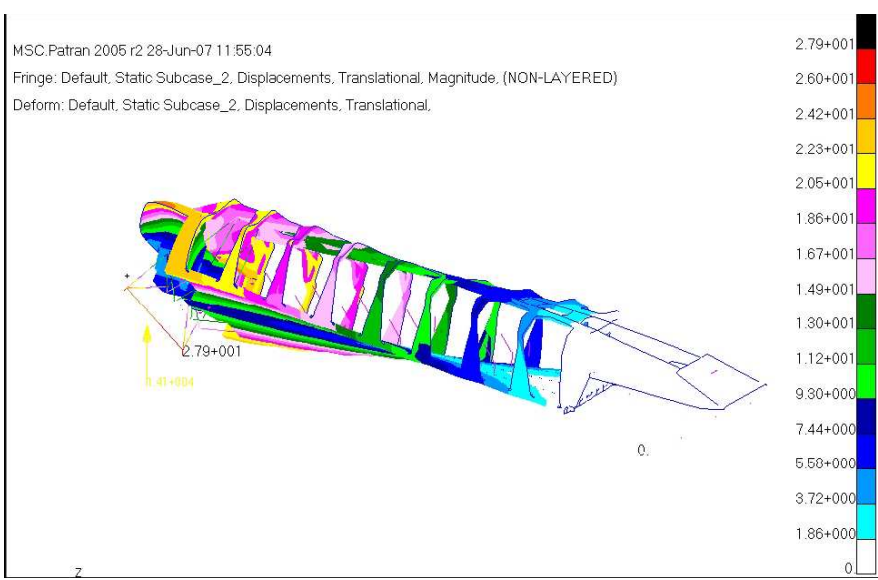

Fig 7: Displacement [mm] at $30.000 \mathrm{Nm}$ torsion load case, Iteration S

Compliance to the bending requirements have proven to be challenging for the stated weight constrains and for the geometrical constraints forced by the overall packaging. The target bending stiffness performance has been achieved by the lay-up modification in the central area and by the introduction of 2 vertical beams in the connecting area between the central cabin and he driver house. These modifications to the structural design have not introduced any significant load increase due to both the relatively low increment in weight itself and the decrease of weight in other areas throughout the optimization.

\section{MATERIALS}

The Superbus structure is built almost completely from carbon-epoxy composites. This allows the weight of the bare structure to be kept to 1300 kilograms, which is exceptional for a 15 meter vehicle. The carbon fiber used throughout is Torayca T700, in three different shapes.

The complete load carrying structure is built using a $12 \mathrm{~K}$ carbon fiber unidirectional tape and stitched tri-axial fabric of $0^{\circ}$ and $+/-45^{\circ}$ carbon fibers, produced by Selcom Srl (Italy), which allows the lay-up to be more efficient compared to a standard lay-up of unidirectional tape and $45^{\circ}$ rotated fabric.

The carbon fiber is used in combination with the latest development of epoxy resin developed for vacuumassisted resin infusion molding by Dow Automotive. This epoxy resin has a very low viscosity and a long pot life, making it ideal for the main Superbus manufacturing process.

Examples of the floor components realized using the materials above are shown in Figure 8a, which shows one of the eight longitudinal floor beams being made, and Figure $8 \mathrm{~b}$ which shows a sample of the finished longitudinal beam.

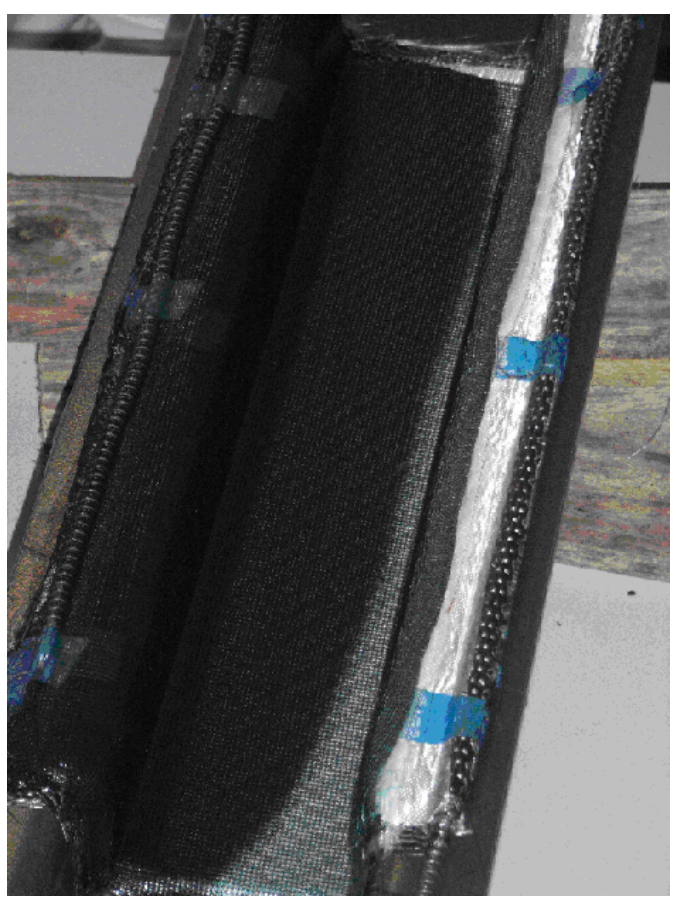

Fig8a: sample of floor beam being built from tri-axial and unidirectional fibers

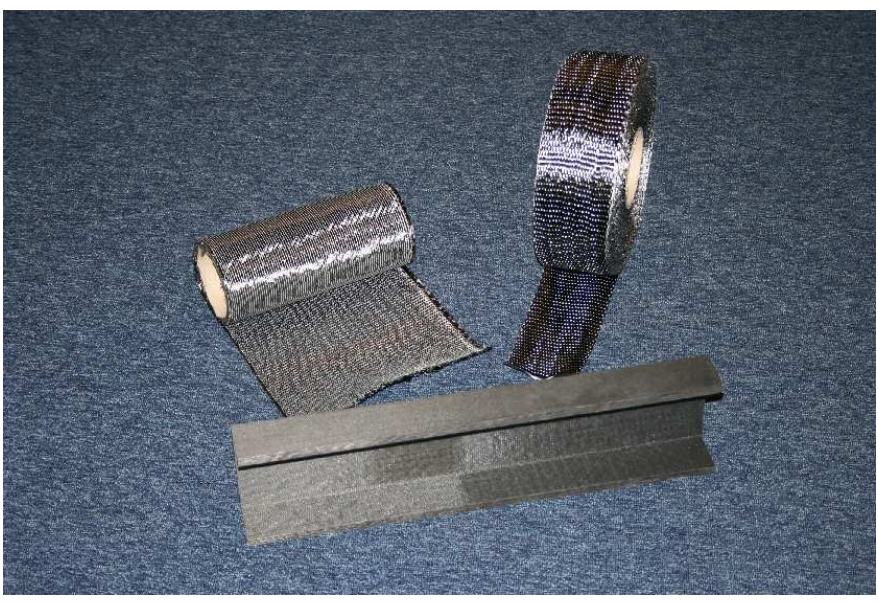

Fig8b: sample of finished floor beam built from tri-axial and unidirectional fibers

Dow Automotive has also supplied tailored made adhesives for the assembly of Superbus chassis and for bonding the Lexan polycarbonate glazing to the chassis.

For the front and rear bodywork parts and the transverse floor beams (Figure 9), carbon fiber of two fabric weights from TenCate (Netherlands) were used. 


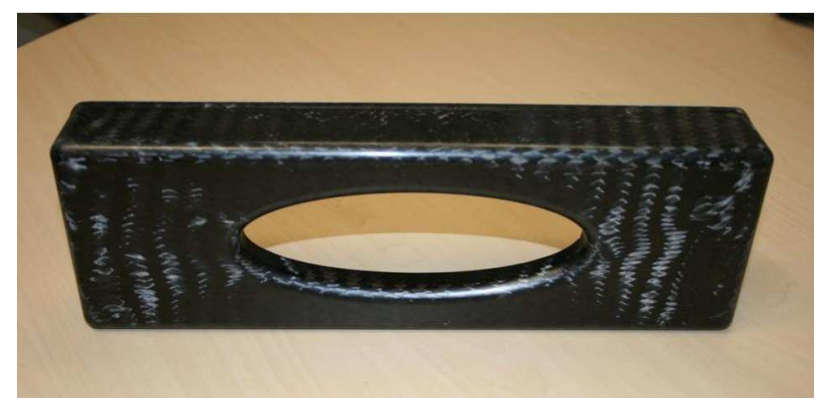

Fig 9: part of one of the transverse floor beams

For the floor skins (Figure 10), for the interior panels and for the front and rear bodywork, Soric core material supplied by Lantor BV (Netherlands) is used. This pressure stable polyester non-woven is ideal as core material for components that are in the area between monolithic parts and sandwich panels using foam or honeycomb.

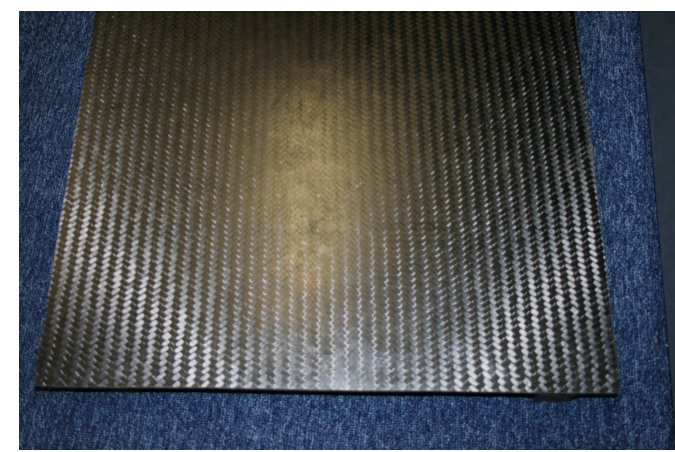

Fig 10: sample of a section of the floor top sandwich plate

A large part of the exterior bodywork will be manufactured from SABIC's latest development in automotive materials: IXIS, which is a thin sandwich consisting of skins of unidirectional glass fibers in a polypropylene matrix and a core of random glass fibers in a polypropylene matrix. This combination results in light-weight panels with excellent impact quality and a Class A finish. IXIS is suitable for both one-off vehicles using simple tooling and a slightly longer cycle time, or with series production tooling and short cycle times. Figure 11 shows the realization of a sample of the exterior bodywork formed to the shape of the $5^{\text {th }}$ door of the Superbus.

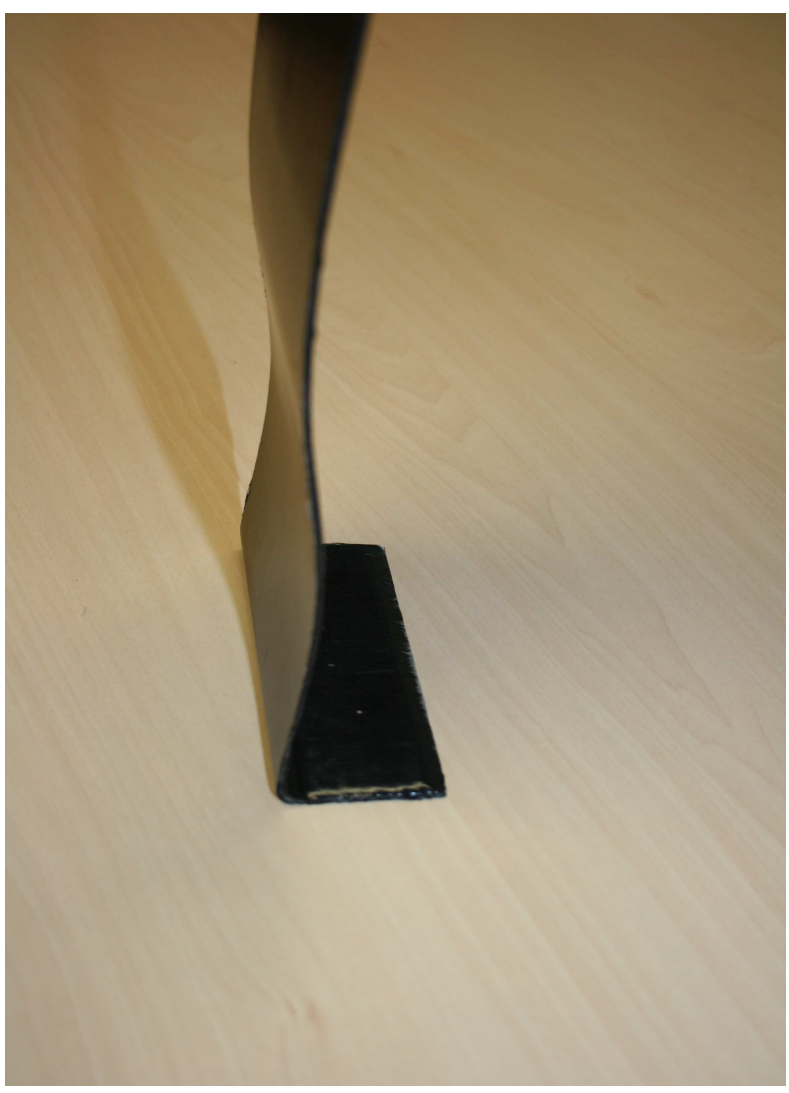

Fig 11: sample of IXIS strip shaped to the contour of 5th door of Superbus

The glazing of Superbus is made of polycarbonate Lexan, supplied by SABIC in two material specifications. For the blue side windows glazing, $6 \mathrm{~mm}$ and IRabsorbtion treated sheets are used. The same material specification could not be used for the front windshield for two reasons. First, because of the structural requirements, that enforced the use of a $10 \mathrm{~mm}$ thick glazing. Second, because of the light transmission requirements which, for the windshield, must to be more than $75 \%$. Therefore, for the windshield, a clear $10 \mathrm{~mm}$ clear polycarbonate Lexan is used.

\section{PRODUCTION}

The floor structure, shown in Figure 12, consists of two sandwich plates, namely top and bottom of the floor, which are produced by vacuum infusion on a flat mould. 


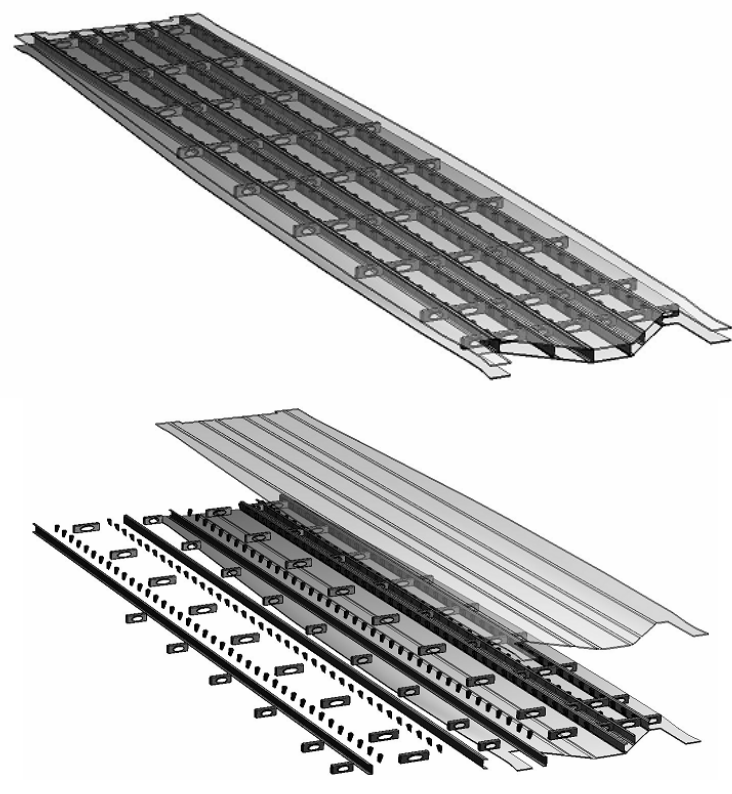

Figure 12: Floor assembly.

The floor skins, which are built on a large sandwich panel that has the required flatness and stiffness, have been optimized in weight, height and stiffness through the utilization of a two millimeter thick type of Soric pressure stable polyester non-woven, used as core material. A number of tests have been carried out in order to ensure that the established stiffness would also comply with passengers comfort level.

The bottom plate includes access hatches. The latter are infused separately on the flat mould, cured, trimmed and replaced on the mould cover by Teflon release film. Then, the bottom plate is infused over the hatches resulting in a flush outer surface.

The longitudinal beams were also made by vacuum infusion in a simple U-shaped sheet metal mould. To ensure a proper mould filling, and to avoid fiber bridging in the negative mould radii, a patented pre-forming process is performed in a separate tool [4].

The transversal beams, due to their amount and dimensions, were produced by hand lay-up. Holes in the webs of these elements allow for the installation of systems like cables and air-conditioning in the floor structure. The whole floor is temporarily joined (before the final bonding) using mechanical fasteners to allow maximum flexibility during the final assembly.

The crossbeam design has come with no little manufacturability challenges. A number of sections of the side structure have been manufactured during the design phase in order to improve manufacturing processes. As shown in fig 13, two beams join to form one beam and then split into two beams again. In the central area, an internal element is needed to ensure the overall structural performance of the frame.

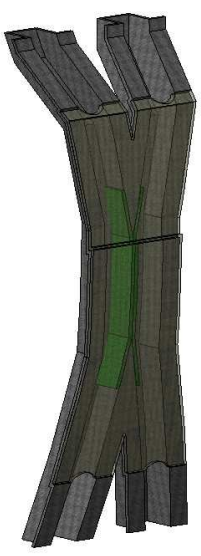

Figure 13: Detail of the framework: the crossbeams

Figure14 shows the realization of the production sample of this complicated section. The test resulted in some recommendation for modifications to the original design with respect to internal radii and release angles.

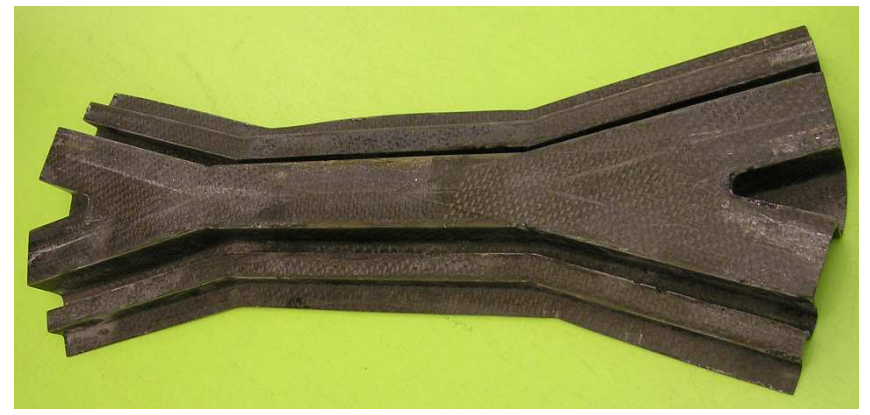

Figure 14: Crossbeam demonstrator produced by vacuum infusion

The frame structure has been made by vacuum infusion [5], using a left and a right mould of the whole central cabin to produce the various elements (Fig 15). The moulds were milled by a low-cost direct tooling route. The shape of the mould was milled with a $5 \mathrm{~cm}$ offset in polystyrene foam. A tooling paste was then applied over the complete surface which, after curing, was milled to the final contour. Finally, coating was applied to produce a smooth and air-tight tool surface 


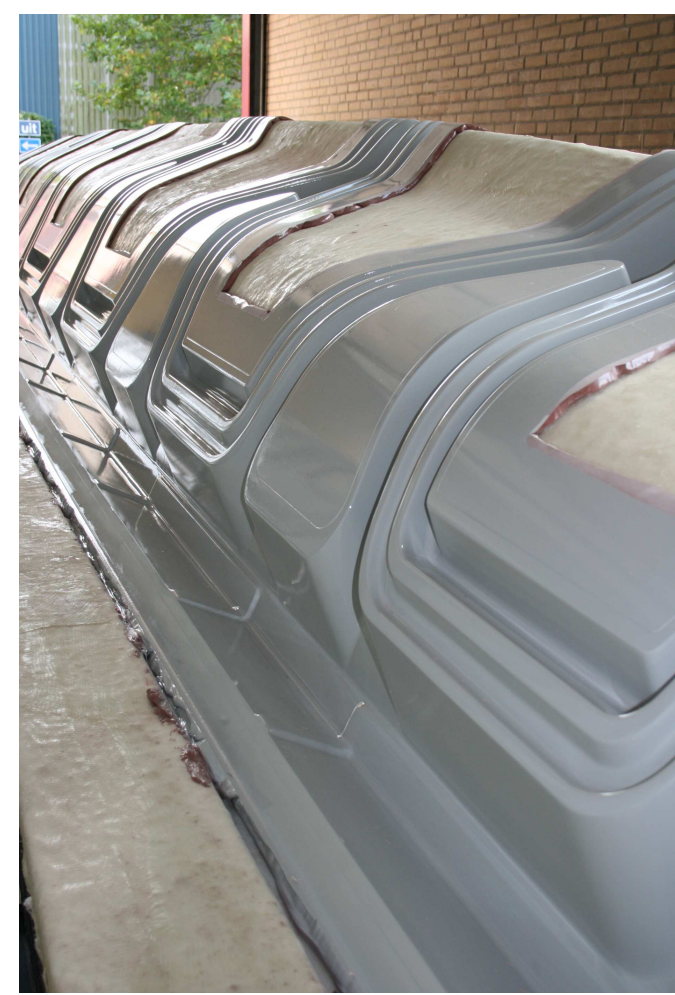

Fig 15 crossbeams side-frames mould

Half of the exterior panels are made from a thermoplastic glass fiber reinforced sandwich laminate, IXIS by SABIC. The moulds for these parts were laminated with a high temperature resistant resin from templates produced from the outer mould. The more complicated body panels, with respect to double curvature and thickness steps, and the load carrying closing panels are produced directly in the outer mould with vacuum infusion in carbon fiber epoxy.

As mentioned above, all glazing parts are formed from polycarbonate sheets. This is a challenging operation as some parts are double curved and present sharp edges. To ensure wear and UV protection, a plasma coating was applied to the formed glazing in a subsequent step.

The body panels and glazing were adhesively bonded to the frame structure to comply with the required aerodynamic smooth surface. The assembled side panels are joined with the floor structure and roof beam elements to form the central part of the body work. Dedicated tooling was used to produce the elements for the driver compartment (including the driver roll-over protection elements) and for the motor and battery compartment.

\section{CONCLUSION}

The Superbus geometrical definition and operational characteristics have rendered the relative structural design and manufacturing of vehicle very challenging. However, the implementation of the crossbeams design, alongside the optimization of central chassis connections to the chassis front part, the lay-up optimization on critical areas and the use of lightweight materials, have enable the achievement of the target low weight, strength and stiffness of the vehicle.

Before final assembly, a number of components will be tested to ensure that the produced pasts reflect the designed parts.

The Superbus will be assembled in February 2008. After the testing, the vehicle will be shipped to Beijing for the official launch which will take place at the 2008 Beijing Olympic Games.

\section{ACKNOWLEDGMENTS}

We wish to thank our sponsors, The Dutch Ministry of Transport and Water Management, Connexxion, TUDelft, Koning and Hartman, SABIC, Vredestein, DOW, and all our suppliers.

\section{REFERENCES}

1. W.J. Ockels, Superbus Dossier, Conceptual Feasibility Study, TU Delft Report, in Dutch (2004)

2. W.J. Ockels, A. Terzi, J. Melkert, Superbus development Program, TU Delft report, in Dutch (2006

3. V. Antonelli, A. Terzi, W.J. Ockels, A. Beukers, Preliminary Design of the Superbus, SAMPE Europe (2007)

4. W.D. Brouwer, E.C.F.C. van Herpt, M. Labordus. Vacuum injection molding for large structural applications. Composites A: Applied science and Manufacturing 34 (2003) 551-558

5. M. Labordus. Composites in high-end applications. The 8th International Conference on Flow Processes in Composite Materials (FPCM8). Douai, FRANCE $11-13$ July 2006 